\title{
A Brief Glimpse at the Long Evolutionary History of Play
}

\author{
Gordon M. Burghardt ${ }^{\text {* }}$ \\ ${ }^{1}$ University of Tennessee, Knoxville \\ *Corresponding author (Email: gburghar@utk.edu) \\ Citation - Burghardt, G. M. (2014). A Brief Glimpse at the Long Evolutionary History of Play. Animal Behavior \\ and Cognition, 1(2), 90-98. doi: 10.12966/abc.05.01.2014

\begin{abstract}
Play has long been considered an enigmatic behavior that is hard to define, but having many putative functions difficult to confirm. This situation is changing quite rapidly in recent years. This introduction to a special issue on play provides some general background, historical and contemporary, on the recognition and phylogenetic aspects of play, along with a discussion on the adaptive functions of play and some recent research findings that might facilitate or extend future research.
\end{abstract}

Keywords - Animals, Evolution, Play, Play definition, Play origins, Play functions, Surplus Resource Theory

The papers in this special section on play behavior derived from talks given at the International Ethological Conference held in New Castle, Great Brittan in 2013 along with additional contributions and cover much ground. Not only are studies on diverse types of play in many species presented, innovative descriptive and experimental methods, both field and captive, are employed. The types of questions asked also indicate the growing maturity of the field in that developmental, evolutionary, causal, and functional issues are all addressed in ways that open new windows into our understanding of these fascinating, important, and long poorly understood phenomena. Additionally, a paper on a play modelling play at the symposium anticipates important advance in play studies as diverse mathematical and quantitative approaches are undertaken to derive testable hypotheses for the processes underlying play.

The papers that follow surely support the claims above. But these papers are only a subset of the wonderful work being done in what can only be called a renaissance of play studies. This is not to say play has been totally neglected. It has always been an important topic in child development and education (see the many chapters in Pellegrini, 2011) and was a topic of much descriptive work and theorizing in animal behavior and ethology. Fagen (1981) and Bekoff and Byers (1981) capture much of this early work and also identified many challenges (updated in Graham \& Burghardt, 2010). In recent decades, however, impressive progress been made, especially in the neural underpinnings of play, though primarily in rodents (Pellis \& Pellis, 2009), developing conceptually rigorous and testable play theories, and in integrating studies of play in human and non-human primates (e.g., Pellegrini \& Smith, 2005).

This paper will serve to introduce to a more general readership some of the concepts useful in the papers that follow, but will emphasize the identification of play, where we currently understand its general distribution in the animal kingdom, focusing on lesser studied taxa, the possible factors underlying the evolution of play, and touch on the hardest nut to crack, perhaps, the adaptive function of play both in the lives of individuals and as an evolutionary process. In short this 'brief history' covers both the evolutionary history of play and the history of some attempts to make sense of it. 


\section{The diversity of play and animals that play}

Animal play is traditionally divided into locomotor/rotational play, object/predatory play, and social play, though all can co-occur and social play does not always need to be with conspecifics. Until recently, however, 'true' play was considered a trait only found in mammals and some birds, with putative examples in other vertebrates and invertebrates dismissed as anecdotal, anthropomorphic conceits, mis-interpreted functional 'instincts,' or maturationally immature behavior (Burghardt, 2005).

There were some major problems in studying the diversity of play, One was the lack of adequate criteria for recognizing play that a) applied to all three major categories of animal play and various typologies of play in humans, b) avoided uncritical anthropomorphism, such as play having to be 'fun' as immediately apprehended by humans, and c) avoided claims of function or adaptive value. We now have criteria that avoid these problems. I developed five criteria (Burghardt 2005, 2011) that can be summarized here: Play is repeated, seemingly non-functional behavior differing from more adaptive versions structurally, contextually, or developmentally, and initiated when the animal is in a relaxed, unstimulating, or low stress setting. This brief version neither captures all the nuances nor is it meant to be the final word, but does help us identify play in animals and contexts previously ignored or prematurely dismissed. This is especially the case with descriptive and anecdotal accounts that did not fit the prevailing view that play was a feature restricted to 'advanced' and 'intelligent' warm-blooded species.

Observational and descriptive accounts of play in even species commonly recognized as playing extensively are now being performed with many animals using the readily available recording and observational methods available today (e.g., Bauer \& Smuts, 2007; Palagi, 2011). Only careful description uncovered the seminal finding that play fighting is not really like serious fighting in many respects (Pellis, 1988), work that has had enormous ramifications. Play has now been documented, with varying levels of detail and study, in many species beyond mammals and birds. Support for the unreferenced examples below can be found in Burghardt (2005) and Graham and Burghardt (2010). We now know that behavior fitting the play criteria above can be found in several species of reptiles. For example Nile softshell turtles knock around basketballs and manipulate hoops and juvenile red-bellied cooters engage in precocial courtship interactions reminiscent of play fighting in rodent. Monitor lizards grab and push around all kinds of objects, shaking shoes and retrieving soda cans like dogs. A salt water crocodile plays with a tethered ball. Dart poison frogs engage in social rough and tumble play. Mormyrid fish push around and manipulate balls and the more social freshwater stingrays play keep-a-way with them. Octopuses manipulate Legos and play catch with balls using their jets. More recently it has been shown that such behavior does not readily habituate and is motivationally robust (Kuba, Byrne, Meisel, \& Mather, 2006). Female wasps in fall engage in harmless social competitions before serious dominance fighting takes place in spring (Dapporto, Turillazzi, \& Palagi, 2006). Sexually immature spiders engage in courtship and psuedocopulatory behavior (Pruitt, Burghardt, Riechert, \& 2012) best described as play. While some disagreements may occur on the precise nature of these putative examples of playfulness (e.g., Bateson \& Martin, 2013), their overall thrust is, in my opinion, beyond debate.

One example of cichlid fish play (Tropheus duboisi) is representative (Burghardt, Dinets, Walsh, \& Murphy, in review). These fish interact with a bottom weighted thermometer involving pushing, jousting, even banging it around the aquarium. Not observed in any other species to date, the behavior is repeated dozens of times every day, and each fish has its own particular style from rather gentle to extremely rough with the object being thrust around the aquarium. The way the thermometer bounces back when struck apparently serves to maintain the fishes' interest in a manner similar to that seen with kittens and human infants. Observations under varying conditions indicate that displaced feeding, courtship, and aggressive interactions cannot explain the behavior in this algae gleaning species. Although there is a long history of claims for play in fishes going back to the $19^{\text {th }}$ Century, fish ethologists and ichthyologists in general never really took such observations seriously (Burghardt, 2005).

These observations all go to support the view that any comprehensive understanding of play needs to accommodate the fact that it is not just limited to endothermic vertebrates. The view that it is so 
limited is probably one reason that biologists did not take the behavior seriously as an important factor in animal behavior and behavioral evolution, but a quirk of some advanced animals poorly understood and whose function was only dimly grasped. We now know that the origins of play and the underlying causal mechanisms go back to very ancient times indeed.

\section{The origins of play}

If play is widely, if sporadically, distributed in the animal kingdom, the question of its origins and evolution is critical. A bottom up, rather than top down, approach seems necessary. By this I mean that to understand the biological and behavioral underpinnings of play we need to look at play in species where it is not widely distributed, complex, or frequent throughout the lifespan, In nonhuman primates every species plays in all three ways as juveniles, and thus it is hard to formulate testable theories of possible evolutionary origins using comparative data. One can, as shown in the work of Pellis and Iwaniuk (1999, 2000), look at adult play, which is less ubiquitous than juvenile play, and relate differences among species to social and ecological factors. Furthermore, progress is being made in understanding the comparative roles and origins of play signals within such groups (Palagi et al. in review).

Social play in rats is perhaps the most well-studied play behavior. Social play is definitely not ubiquitous in rodents, however, allowing for more precise identification of candidate processes underlying comparative differences and to test hypotheses. However, even within Rattus norvegicus recent studies of different breeds of rats and wild conspecifics has documented important differences that will lead to fruitful studies of the mechanisms involved (Himmler et al., 2013). This is relevant, perhaps, to studies in human and non-human primates showing geographical differences in the amount and kinds of play (Burghardt, 2005; Lancy, 2008).

But what about the factors that may underlie play in its more basic atavistic forms before evolving into the often complex forms seen in many animals today and which have design features and costs indicative of often specific benefits? Building on observations that some play may have minimal benefits and not be an adaptation (Burghardt, 1984), I have proposed that play develops originally from a series of primary processes, such as lack of stimulation, excess metabolic energy, etc. into complex forms that both maintain (secondary) and enhance physiological, behavioral and mental traits in their many iterations, perhaps even fostering novel and creative behavior (tertiary processes in Figure 1). This preliminary scheme may be useful in classifying and developing testable hypotheses. The advent of prolonged ontogenies and parental care may have facilitated this process comparable to domestication (Burghardt, 1988).

One of the enduring issues is why play is so prominent in primates, including humans, as compared to most other taxa. Surplus Resource Theory (SRT), which included metabolic factors as a major component, postulated that species with more time and energy resources, or active in, for example, aquatic environments where costs of locomotion are reduced, would play more and that this would hasten the transitions between Primary, Secondary, and Tertiary play. Cetaceans, as described in this issue by Kuczaj and Eskelinen, certainly fit this model. Yet primates, with their large brains, presumably use many resources for simple maintenance of their brain, which might make excess activity more expensive! Yet these are the very animals that play the most, as a group. This complication has been recently removed by work showing that primates, as a group, use less, not more, energy for maintenance and growth than other mammals, with momentous consequences for life history (Pontzer et al., 2014). The underlying mechanisms are little understood, but if primates evolved a more efficient energetic system than other mammals this may have hastened transitions to extensive play and resulting novel behavior and cognitive attainments.

Aspects of play involving causal and development processes are major and critically important factors in current research and also treated in the papers that follow (also see Pellegrini, 2009, 2011; Pellis \& Pellis, 2009; Smith, 2010). However, I will limit my additional comments to the perennial quest for the adaptive value of play, which, however, often relies on developmental and neuroscience research. 


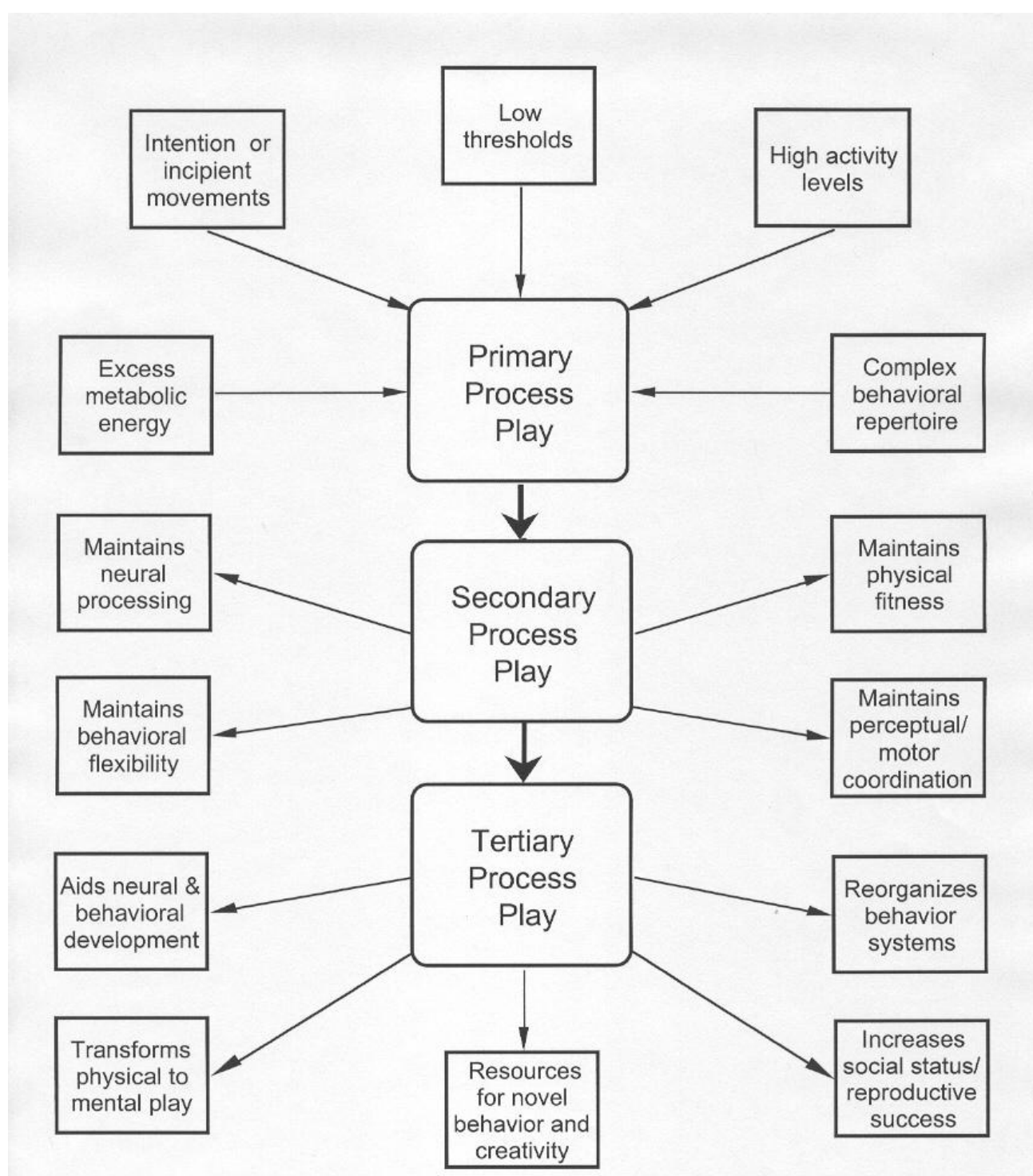

Figure 1. A scenario for the evolution of play depicting three play processes. Note that all three processes can occur in the same species and individual depending on setting, context, experience, etc. (from Burghardt, 2005).

\section{The functions of play}

A major conclusion from the comparative data is that play is a very heterogeneous phenomenon in terms of its origins, both ancient origins and those within lineages involving families and genera. This has major implications for the search for the functions of play. A primary focus in the history of the study of play has been developing theories for the function of play and the competition among them (Burghardt, 2005; Fagen, 1981). This focus continues to the present, and rightly so, as we need more and better theories and tests among them. In spite of many claims, a sobering review (Martin \& Caro, 1985) found precious little support for any proposed functions, most of them reasonable, and such negative conclusions have continued to the present (Sharpe, 2005a, b, c; Sharpe \& Cherry, 2003). Some papers in this issue address play functions in terms of both the role of elements of play in the play itself, especially important in social play, and play function in the larger sense of its adaptive role in the context of specific behavior (e.g., foraging), its role in individual life histories (survival), reproductive and inclusive fitness, 
and its putative role in the evolution of behavior more generally. These different meanings of function need to be kept in mind in evaluating the evidence, and especially what the evidence means.

In decades past there were searches for THE function of play - practice for adult skills of various types was predominant, a view that goes back to Groos (1898), and still contested. Reviews of the functions of play from various perspectives are available in Fagen (1981), Power (2000), Burghardt (2005), Pellis and Pellis (2009), Smith (2010), Pellegrini (2009), Bateson and Martin (2013) and others. Approaches now being explored include a focus on immediate benefits to the player such as physical conditioning and perceptual motor abilities (e.g., learning about objects and partners), shaping the brain and behavior during critical ontogenetic phases, and aiding reproductive success and survival. Pellis and Pellis (2009) and Bateson and Martin (2013) focus on social adeptness and novelty creation, respectively, illustrating the range of interests being addressed. The stimulating training for misfortune hypothesis (Špinka, Newbury, \& Bekoff, 2001) has received much attention also, but so far supporting tests are apparently not available. The related, more general, self-assessment theory (Thompson, 1998) may have more support in, for example, the motivational and affective aspects of 'learning' to walk in human infants (Burghardt, 2005).

However, I think we are increasingly discovering several key points that derive from both the heterogeneous nature of play, the failed tests of seemingly obvious functions, and increased methodological sophistication in formulating and testing ideas. First there is the recognition that a putative function of play may be accomplished through other, even multiple means that do not involve play at all (e.g., Smith, 2010). Second, the great diversity of play suggests that any supported function of play may be quite specific to the type of play as well as the species involved. Third, primary process play will have no direct adaptive functions at all, being byproducts of other systems that, none the less, provide behavioral variation for later functional evolution. We are, in fact, now seeing 'micro theories' of play tested empirically with specific taxa. One play size does not fit all.

A further point is the need to be careful to recognize that not all supporting data are equal, and that is particularly relevant in the study of play. There are 6 methods that I think can and have been used (Burghardt, 2005). These include, cost-benefit analysis (if the behavior is costly in energy, survival, etc. then it must be adaptive), and the more specific design feature approach in which behaviors like cats playing with rubber mice and rats play fighting functions to aid in real hunting or fighting just because they are obviously designed to do so. Can we not decipher the diet of birds from the design of their beaks? Both these weak approaches must now be viewed as merely suggestive but in no way supportive of any functional claim. Comparative phylogenetic studies involve mapping play and other traits on a phylogeny (ranging from populations to genera and above) and tracking associations between traits to test putative associations. This has been done testing, for example, the association of adult social and nonsocial play with social organization and other factors (Pellis \& Iwaniuk, 1999, 2000). A similar analysis tests the relationship between folivory and frugivory on adult play in primates. In these cases, modern methods can even, if sample sizes suffice, parse out the directionality and rapidity of evolution (Burghardt, in press; O'Meara et al. in prep). Such methods, with extensive databases, can actually serve as critical tests of evolutionary hypotheses for play. Their ability to directly confirm function, however, must still be considered correlational. Variants of this approach look at the developmental timing of play behavior and some measures of neurological development across several species, as in the Byers and Walker (1995 attempt to support the motor training theory and the finding that styles of play within a single genus of monkeys is related to social organization (Reinhart et al., 2010)

This comparative correlational approach needs to be distinguished from the adaptive correlational approach. Laboratory studies may record measures of juvenile play with objects or social partners and then assess, at a later time, how efficient the animals are at foraging or their social rank, for example. As mentioned, many such studies have not been successful. These studies rely on natural variation in two or more traits. This method I think is most useful in long-term field studies showing, for example, that brown bears that play more as cubs lead to better rates of survival, that the authors suggest, is due to an emotional resilience that allows them to more competently deal with dangers and unpredictable events (Fagen \& Fagen, 2004, 2009). More recently, Blumstein, Chung, and Smith (2013) 
document that juvenile play is related to later social dominance in yellow-bellied marmots, Here, an energy and time costly behavior has a benefit later in life. Studies of wild monkeys show that play facilitates peaceful interaction with strangers (Antonacci, Norscia, \& Palagi, 2010). In fact, a stress regulation function for play may prove to be a major aspect of play.

Experimental studies, the fifth method, are, however, needed, to produce the most convincing data on play functions. These relate to both survival and reproductive fitness. Play deprivation studies are notoriously difficult and hard to interpret, but experimental progress is being made with innovative methods and these show that social play in rats, for example, has effects on both behavior and brain in rats (Bell, Pellis, \& Kolb, 2010; Pellis \& Pellis, 2009; Pellis, Pellis, \& Bell, 2010; van den Berg et al., 1999). With the rapid development of neuroscience it seems likely that experimental studies of the function of play in laboratory model animals will increase rapidly. Non-invasive methods may soon allow such studies with other animals including nonhuman primates. As for showing the importance of play in terms of fitness, the most convincing current evidence is from spiders, where it has been shown that immature spiders allowed to engage in precocial courtship (which fulfills the 5 play criteria) have benefits for both survival and reproduction. Males with precocial courtship experience are far more likely to survive courtship without being killed or eaten by the larger and aggressive females, and females with such precocial courtship experience lay larger egg cases containing many more eggs.

The last method is one which will grow in value in future years, the mathematical and modeling approach. Pioneered by Fagen in the late 1970s (Fagen, 1981) it has been largely dormant in recent years, with the exception of the fairness model (Bekoff, 2004) that predicted that social play should converge on a 50:50 ratio of wins to losses in a given pair of players. This is only recently been subjected to testing (e.g., Bauer \& Smuts, 2007), but such tests show that models can lead to empirical work. More modeling is soon to come facilitated by, for example, initiatives such as the working group on Play, Evolution, and Sociality sponsored by the NSF supported National Institute for Mathematical and Biological and (NIMBioS).

If any general theory of play function is emerging, the role of play in regulating emotion and stress may be very promising, as it can be involved in many diverse types of play and various contexts. For example, solitary play can be affected as much as the social play examples noted above. This intriguing, and somewhat unexpected idea, will perhaps lead to a more nuanced deployment of the play criterion that play is initiated in low stress situations. While this remains true for chronic or severe stress, the role of play in relieving or addressing mild stress (including boredom) and providing resiliency for dealing with stressful events one encounters, may become more prominent.

One should always be vigilant for other possible functions of play at any level (within play, development, sociality, cognition, fitness). For example, Mischel, Llewellyn-Smith, and Mueller (2014) documented that activity in itself promoted neuronal development in the rat medulla, supporting suggestions that play serves to aid brain and physiology irrespective of the specific activity performed. Thus play may have initially evolved to keep the animal active (Burghardt, 1988). Even more interestingly, Wu, Miyamoto, Castro, Ölveczky, and Smith (2014) have shown in experiments with humans, that variability in motor movements, rather than the amount, leads to enhanced motor learning. Although the authors relate their findings to reinforcement theory, the fact that play, especially social play, involves active parries and thrusts, actions and reactions, suggests that play may be a major source for such variability and enhanced learning abilities. Together these suggest that play may be an important, though not exclusive, means of enhancing both behavioral and cognitive abilities.

\section{Conclusions}

In this short introduction I have tried to present a few selective comments on the fascinating phenomena of play. It is clear that play in a wide variety of species is being increasingly studied in detail by many laboratories. Although disparate phenomena at one level, I think it important that those working on social play keep up with the literature on other types of play and vice versa. Similarly, those working on play in children should know what is being done in primate play and those working with nonhuman 
primates should keep up with those working on carnivores, rodents, birds, and nontraditional species. Again, such interests need to be reciprocated. Play research, as an interdisciplinary field, benefits greatly from findings in many other fields and researchers need to keep abreast of these trends and accommodate new theoretical and methodological approaches that have, and will continue to, enrich our understanding.

\section{Acknowledgments}

I thank the many colleagues and students who have studied play so effectively over the years and aided both my thinking and the empirical studies discussed here. NIMBioS at the University of Tennessee funded my participation at the IEC Symposium and the manuscript was written while a Resident Scholar at the Center of Theological Inquiry in Princeton, NJ.

\section{References}

Antonacci, D., Norscia, I., \& Palagi, E. (2010). Stranger to familiar: Wild strepsirhines manage xenophobia by playing. PLoS One, 5, http://dx.doi.org/10.1371/journal.pone.0013218.e13218

Bateson, P., \& Martin, P. (2013). Play, playfulness, creativity and innovation. Cambridge, UK: Cambridge University Press.

Bauer, E. B., \& Smuts, B. B. (2007). Cooperation and competition during dyadic play in domestic dogs, Canis familiaris. Animal Behaviour, 73, 489-499.

Bekoff, M. (2004). Wild justice, cooperation, and fair play: Minding manners, being nice, and feeling good. In R. W. Sussman \& A. R. Chapman (Eds.), The origins and nature of sociality (pp. 53-80). New York, NY: Aldine de Gruyter.

Bekoff, M., \& Byers, J. A. (1981). A critical reanalysis of the ontogeny and phylogeny of mammalian social and locomotor play: An ethological hornet's nest. In K. Immelmann, G.W. Barlow, L. Petrinovich, and M. Main (Eds.), Behavioral development: The Bielefeld interdisciplinary project (pp. 296-337). Cambridge, UK: Cambridge University Press.

Bell, H. C., Pellis, S. M., \& Kolb, B. (2010). Juvenile peer play experience and development of the orbitofrontal and medial prefrontal cortices. Behavioural Brain Research, 207, 7-13.

Blumstein, D. T., Chung, L. K., \& Smith, J. E. (2013). Early play may predict later dominance relationships in yellow-bellied marmots (Marmota flaviventris). Proceedings of the Royal Society B, Biological Sciences, 280, doi: 10.1098/rspb.2013.0485

Burghardt, G. M. (1984). On the origins of play. In P. K. Smith (Ed.), Play in animals and humans (pp. 5-41). Oxford, UK: Blackwell.

Burghardt, G. M. (1988). Precocial behavior, play, and the ectotherm-endotherm transition: Profound reorganization or superficial adaptation? In E. M. Blass (Ed.), Handbook of neurobiology, Vol. 9, Developmental psychobiology and behavioral ecology (pp. 107-148). New York, NY: Plenum Press.

Burghardt, G. M. (2005). The genesis of animal play. Testing the limits. Cambridge, MA: MIT Press.

Burghardt, G. M. (2011). Defining and recognizing play. In A. D. Pellegrini (Ed.). The Oxford handbook of the development of play (pp. 9-18). Oxford, UK: Oxford University Press.

Burghardt G. M. (in press). The origins, evolution, and interconnections of play and ritual: Setting the stage. In C. Renfrew, I. Morley, \& M. Boyd (Eds.) Play, ritual and belief in animals and in early human societies. Cambridge, UK: Cambridge University Press.

Burghardt, G. M., Dinets, V., Walsh, T., \& Murphy, J. B. (2014). Highly repetitive object play in a cichlid fish (Tropheus duboisi). Manuscript submitted for publication.

Byers, J. A., \& Walker, C. (1995). Refining the motor training hypothesis for the evolution of play. American Naturalist, 146, 25-40.

Dapporto, L., Turillazzi, S., \& Palagi, E. (2006). Dominance interactions in young adult paper wasp (Polistes dominulus) foundresses: A playlike behavior? Journal of Comparative Psychology, 120, 394-400.

Fagen, R. A. (1981). Animal play behavior. New York, NY: Oxford University Press.

Fagen, R., \& Fagen, J. (2004). Juvenile survival and benefits of play behaviour in brown bears, Ursus arctos. Evolutionary Ecology Research, 6, 89-102.

Fagen, R., \& Fagen, J. (2009). Play behaviour and multi-year juvenile survival in free-ranging brown bears, Ursus arctos. Evolutionary Ecology Research, 11, 1053-1067.

Graham K. L., \& Burghardt, G. M. (2010). Current perspectives on the biological study of play: Signs of progress. 
Quarterly Review of Biology, 85, 393-418.

Groos, K. (1898). The play of animals. New York, NY: Appleton.

Himmler, B. T., Stryjek, R., Modlinska, K., Derksen, S. M., Pisula, W., \& Pellis, S. M. (2013). How domestication modulates play behavior: A comparative analysis between wild rats and a laboratory strain of Rattus norvegicus. Journal of Comparative Psychology, 127, 453-464. doi: 10.1037/a0032187

Kuba, M. J., Byrne, R. A., Meisel, D. V., \& Mather, J. A. (2006). When do octopuses play? Effects of repeated testing, object type, age, and food deprivation on object play in Octopus vulgaris. Journal of Comparative Psychology, 120, 184-190.

Lancy, D. F. (2008). The anthropology of childhood: Cherubs, Chattel, changelings. Cambridge, UK: Cambridge University Press.

Martin, P., \& Caro, T. (1985). On the function of play and its role in behavioral development. Advances in the Study of Animal Behavior, 15, 59-103.

Mischel, N. A., Llewellyn-Smith, I. J., \& Mueller, P. J. (2014). Physical (in)activity-dependent structural plasticity in bulbospinal catecholaminergic neurons of rat rostral ventrolateral medulla. Journal of Comparative Neurology, 522, 499-513. doi: 10.1002/cne.23464

Palagi, E. (2011). Playing at every age: Modalities and potential functions in non-human primates. In A. D. Pellegrini (Ed.), Oxford handbook of the development of play (pp. 70-82). Oxford, UK: Oxford University Press.

Palagi, E., Burghardt, G. M., Smuts, B., Cordoni, G., Dall’Olio, S. Fouts, H. N., Řeháková-Petrů. M., Siviy, S. M., \& Pellis, S. M. (2014). Rough-and-tumble play as a window on animal communication. (2014). Manuscript submitted for publication.

Pellegrini, A. D. (2009). The role of play in human development. New York, NY: Oxford University Press.

Pellegrini, A. D. (2011). Oxford handbook of the development of play. Oxford, UK: Oxford University Press.

Pellegrini, A. D., \& Smith, P. K. (2005). The nature of play: Great apes and humans. New York, NY: Guilford Press.

Pellis, S. M. (1988). Agonistic versus amicable targets of attack and defense: Consequences for the origin, function, and descriptive classification of play-fighting. Aggressive Behavior, 14, 85-104.

Pellis, S. M., \& Iwaniuk, A. N. (1999). The problem of adult play: A comparative analysis of play and courtship in primates. Ethology, 105, 783-806.

Pellis, S. M., \& Iwaniuk, A. N. (2000). Adult-adult play in primates: Analyses of its origin, distribution and evolution. Ethology, 106, 1083-1104.

Pellis, S. M., \& Pellis, V. C. (2009). The playful brain. Venturing to the limits of neuroscience. Oxford, UK: Oneworld Press.

Pellis, S. M., Pellis, V. C., \& Bell, H. C. (2010). The function of play in the development of the social brain. American Journal of Play, 2, 278-296.

Pontzer, H., Raichlen, D. A., Gordon, A. D., Schroepfer-Walker, K. K., Hare, M. C. ...Ross, S. R. (2014). Primate energy expenditure and life history PNAS, published online January 13, 2014. doi:10.1073/pnas.1316940111

Power, T. G. (2000). Play and exploration in animals and children. Mahwah, NJ: Lawrence Erlbaum Associates.

Pruitt, J. N., Burghardt, G. M., \& Riechert, S. E. (2012). Nonconceptive sexual behavior in spiders: A form of play associated with body condition, personality type, and male intrasexual selection. Ethology, 118, 33-40.

Reinhart, C. J., Pellis, V. C., Thierry, B., Gauthier, C. A., VanderLaan, D. P., ... Pellis, S. M. (2010). Targets and tactics of play fighting: Competitive versus cooperative styles of play in Japanese and Tonkean macaques. International Journal of Comparative Psychology, 23, 166-200.

Sharpe, L. L. (2005a). Play fighting does not affect subsequent fighting success in wild meerkats. Animal Behaviour, 69, 1023-1029.

Sharpe, L. L. (2005b). Play does not enhance social cohesion in a cooperative mammal. Animal Behaviour, 70, 551558.

Sharpe, L. L. (2005c). Frequency of social play does not affect dispersal partnerships in wild meerkats. Animal Behaviour, 70, 559-569.

Sharpe, L. L., \& Cherry, M. I. (2003). Social play does not reduce aggression in wild meerkats. Animal Behaviour, 66, 989-997.

Smith, P. K. (2010). Children and play. Chichester, UK: Wiley-Blackwell.

Špinka, M., Newbury, R. C., \& Bekoff, M. (2001). Mammalian play: Can training for the unexpected be fun. Quarterly Review of Biology, 76, 141-168.

Thompson, K. V. (1998). Self assessment in juvenile play. In M. Bekoff \& J. A. Byers (Eds.), Animal play: 
Evolutionary, comparative, and ecological perspectives (pp.183-204). Cambridge, UK: Cambridge University Press.

van den Berg, C. L., Hol, T., van Ree, J. M., Spruijt, B. M., Everts, H., \& Koolhaas, J. M. (1999). Play is indispensable for an adequate development of coping with social challenges in the rat. Developmental Psychobiology, 34, 129-138.

Wu, H. G., Miyamoto, Y. R., Castro, L. N. G., Ölveczky, B. P., \& Smith, M. A. (2014). Temporal structure of motor variability is dynamically regulated and predicts motor learning ability. Nature Neuroscience, doi:10.1038/nn.3616 